\title{
On the Margins of SoTL Discourse: An Asian Perspective ${ }^{1}$
}

\section{ABSTRACT}

The International Society for the Scholarship of Teaching and Learning (ISSOTL) began in 2004, constituted by 67 scholars, mostly from English-speaking countries located in the Western hemisphere. Since then, the world has become increasingly global and borderless, and students' movements across continents in search a good education have meant that today's classrooms are, in varying degrees, heterogeneous. Yet SoTL discourse-the metaphors employed, the issues identified, and SoTL methods or approaches to classroom practice-have remained largely Western in orientation.

This paper describes three types of exclusions of Asian participants and perspectives in mainstream discourse on the SoTL: geographical isolation, methodological solipsism, and ideological exclusion. Through a review of the dominant scholarship, we argue that an international association like ISSOTL must take active steps to consciously acknowledge the need for alternative voices that are located outside its immediate realm and that the differences in practice, participants, and the politics of culture in locations outside the West need to be taken into consideration, or ISSOTL will risk losing relevance for a greater part of world. Or to put it more positively, ISSOTL has much to gain by paying attention to and not denying the existence of such enriching, if less familiar, perspectives.

\section{KEYWORDS}

situated classroom practice, ideological exclusion, Asian perspective, unexplored participants, broadening SoTL discourse space

\section{PROLOGUE}

\section{Huang Hoon's Story}

Like many academics, she was trained in a subject discipline and not in education. And like many colleagues working in most universities in the 1990s, she has never undergone a formal teacher training programme: she was just assumed to know how to teach just because she has successfully pursued a $\mathrm{PhD}$. Hers was thus an unremarkable journey in teaching and learning in higher education. For the most part, she taught intuitively, not in any formal, pedagogically informed way. And in intuitively knowing what works for 
her students, she has been amply rewarded with multiple teaching recognitions in her two decades with her university, including an appointment as director to her university's teaching and learning centre in 2008.

Fast forward. 2012 started with a surprise email invitation to serve on the Editorial Board of a new ISSOTL journal. This was a surprise in two ways: she has had no previous formal contact with this SoTL network other than to count a few scholars among her personal/professional contacts, and she has not in her wildest dreams ever considered herself an expert ${ }^{2}$ in the teaching and learning world. Still, what a pleasant way to start a new year-and what an honour! With mixed feelings - due largely to a nagging feeling that SoTL is an alien territory, and in part to a fear of a less than familiar path ahead-she accepted the invitation after the editors assured her that she will lend a different perspective to the journal's board.

The full board was assembled in the quickest time, and the first order of business was to arrive collectively at a name for the new journal. Her fear of the unknown soon deepened. She found herself quite unfamiliar with the conversation that took place over this matter. There was one particular debate over the word "Commons": one group supported the use of the word 'commons' - one colleague said it has "a positive history with the Society" (Gary Poole, UBC, Canada) 3 , but others felt the word 'commons' is less familiar to those located outside the immediate SoTL circle. She was relieved to know that she is not the only one who could not identify with the history of and the discourse about 'commons.' When the final decision was taken not to have 'commons' in the name of the journal, she rejoiced and she looked forward to other gestures of inclusion in future interactions.

\section{Peter's Story}

Like Huang Hoon's, Peter's story began in much the same way. He had no idea how to teach and approached teaching nervously. There was no framework within which to understand teaching other than his own experiences as a student, though he might not have explained it like that back then. Ten years later, with a tenured position at the University of New South Wales, he went on to win a university teaching award. When occasion demanded it, he discovered how much he enjoyed the process of reflecting on what he was trying to achieve with students. In 2002, he was awarded a six-month teaching and learning fellowship with 14 other faculty members. This culminated in a one-year appointment to the Learning and Teaching Unit, followed by a full time career as a faculty developer, working with faculty and helping to develop and implement policy on learning and teaching.

His first contact with ISSOTL was at the inaugural ISSOTL conference held in 2004. He became one of three Australian members of the Carnegie Foundation for the Advancement of Learning groups (RUCASTL). At this time, he felt that he was at the centre of a world movement, one that would lead to important changes in thinking about higher education. But occasionally he felt that something about his 'funny' accent and his vocabulary made him less visible.

Then, over a period of two years he worked in chunks of two or four weeks as a consultant in Hong Kong with John Biggs and Catherine Tang on the Hong Kong OutcomesBased Teaching and Learning Project. This meant working in different cultural circum- 
stances, and he became aware of the need to pull back from his own cultural assumptions. Recognising the depth of his own cultural habits is not easy, he found, and it is a constant process of discovery and reflection.

His brief affiliations since 2007, with both UNSWAsia in Singapore and the Centre for Teaching and Learning at the University of Newcastle and later Nanyang Technological University (NTU) in Singapore, made him certain that teaching and learning at university are encased in quite different contexts from one place to another, and scholarship conducted in one context does not necessarily apply in another. In Singapore, now the Associate Director of his university's teaching and learning unit, he feels as if he has moved from the centre to the periphery of the SoTL map. Faculty at NTU rejected some SoTL work as "Western," not applicable to the Singapore students (and education system), and he agrees with them.

At the closing of the first ISSOTL Conference in Bloomington, Indiana, when inviting delegates to the next conference across the border in Vancouver, Gary Poole quipped, "And you'll be the guys with the accents." ${ }^{4}$ Poole reminded us then that accents are relative to our own "neutral" speech. An immigrant who has been in a country for years might be told that she has nearly lost her accent, rather than that she has begun to acquire the accent of her adoptive country. But in shifting the "neutral" ground from the US to Canada, Poole drew attention to the fact that we all have accents.

What Huang Hoon and Peter have both learnt through their own trajectories - from a focus in a subject discipline to education and from Australia to Asia-is the importance of being explicit about the fact that we all have "accents." It's not just the other people. Additionally, internationalisation does not simply mean being inclusive of those with accents; it means also hearing our own.

\section{AIMS}

This paper was borne out of a feeling of existential isolation, of having been left out of a conversation. While the exclusion may not have been intentional, it is no less disempowering. The fact is, one of us was never part of the SoTL world - she is a linguist by training and took up an administrative appointment to direct a teaching and learning center for a few years, and in those few years when she was learning the job, had little contact with SoTL scholarship. The other had been more "privileged," as he was once a bona fide member, well situated within the circle, but then dropped out when he travelled from centre (i.e., Australia) to margin (i.e., Hong Kong/Singapore) and found it difficult to gain re-entry from a different location. Both of them are now among the (Asian) voices situated physically and psychologically at the margins of SoTL discourse, part of a sector of an unexplored audience, hitherto excluded from the SoTL world. In different ways then, and in more ways than one, we in Asia are situated at the outermost edge of the dominant discourse emanating from the SoTL world, excluded from SoTLspeak and tradition.

This paper aims to do a number of things. One, we wish to map out the geographical, methodological, and ideological isolation that we have experienced, sited as we are in one far corner of Asia. Two, we hope to make an appeal to SoTL scholars to consider broadening the SoTL discourse space to include Asian perspectives. Three, we wish to show that by excluding Asia, SoTL has missed the opportunity to investigate a set of intriguing challenges that are peculiar to Asia. And finally, we argue that by bringing Asia (and 
for that matter, all other unexplored audiences) to the table, SoTL stands to benefit from a broadened ideological realm and can become a genuinely international organization.

\section{DOCUMENTING AN ABSENCE: THE SOTL SCHOLARSHIP}

The Scholarship of Teaching and Learning (SoTL) movement is shadowed by persistent questions of definition, the role of theory, and the place of disciplinary epistemologies in shaping enquiry (Brew, 2011; Draeger \& Price, 2011; Gossman et al., 2009; Haigh, 2010; Healey, 2000 \& 2008; Kreber, 2007; Prosser, 2008). Dewar (2008) notes an "increasing introspection" (p.17) with regard to SoTL in the January 2008 issue of International Commons while Stefani (2011) asks whether "we are not laboring too much on the finer nuances of a definition" (p.2). Nevertheless, many of the questions asked about the scholarship of teaching and learning may be intrinsic to the role played by the contexts within which teaching and learning are seen to occur. An emerging question for SoTL is how to account for genuinely cross-cultural contexts.

It should be said at the outset that the question of cultural difference and cultural diversity in relation to education is a complex one and that we are talking about one particular aspect of it. There is perhaps increasing cultural diversity within the classroom, perhaps nowhere more so than in Western universities. As Delpit (2006) so trenchantly points out, differences between school culture and home culture in a culturally diverse society like the US can lead to many forms of misunderstanding and miscommunication of intentions and that requires creating "multicultural curricula that educate our children to the differing perspectives of our diverse population” (Delpit, 2006, p. 177). Not only is there diversity in the student population, but also among teachers. We speak here of Asia, and of course there are many students from Asia in universities around the world. However, a culturally diverse classroom in the US and a culturally diverse classroom in Singapore are still both encased in larger contexts that make them different from each other on the basis of institutional cultures, political cultures, and beliefs about education. In considering context, both these levels of cultural difference need to be taken into account, but they cannot be flattened into the same thing.

A key distinction often made between SoTL and education research is that the former involves disciplinary teachers investigating specific classroom contexts, whereas the latter involves the generation of general theories of education and learning (Haigh, 2010). SoTL is frequently seen as an investigation of situated classroom practice: it is "about the teaching-learning process, it is about the teacher's understanding of the process within a context" (Gurm, 2009, pp. 7-8). Questions about the role of theory, the disciplines, and the specificity of other contexts lead to more fundamental questions about the SoTL enterprise in terms of generalizability (Schroeder, 2007). Can specific practice be generalized? Communicating results, ideas, and practice- "going public"-in order to influence practice beyond specific contexts is, however, one of SoTL's underlying principles (Hutchings \& Shulman, 1999; Trigwell, et al., 2000). Tensions in SoTL therefore arise between the specific (contextual) and the general (making sense of the contextual for others). For Prosser (2008), SoTL is an "interplay between the generic and the contextual" (p. 3). But Looker (2011) asks where the boundaries of meaningful context might lie in this formulation when investigating teaching and learning in situ. What are the contexts of the classroom? Bringing cultural contexts to bear may require rethinking what is reported in SoTL investigations. 
Other scholars have also questioned the narrowness of context currently demonstrated by SoTL work (Boshier \& Huang, 2008; Clegg, 2008). Boshier and Huang suggest that SoTL "foregrounds teaching and backgrounds learning" (2008, p. 649), and they remind us that the context in which teaching and learning take place is also socio-political, involving "power relationships and cultural exchange" (p. 654). Clegg (citing Boshier) asks what kind of education is privileged or marginalised by SoTL. She raises the question of SoTL's national and institutional assumptions, noting a tendency to under cite the "brilliant work" in SoTL coming from South Africa.

In the beginning, the scholarship of teaching and learning movement as embodied in the acronym 'SoTL' was largely a US concept (Brawley et al., 2009). McKinney (2007) notes that membership of ISSOTL is largely North American and Western. The Multinational Scholars Forum (emphasis added) reported on by Reynolds (2008) consists of scholars from the UK, Canada, the USA, and New Zealand, the same countries (excepting New Zealand) that have to date hosted the annual ISSOTL conference: USA (four times), Canada (twice), UK (once), and Australia (once). Other major conferences include the Annual Midwest Conference on the Scholarship of Teaching and Learning (13 times) and the London Scholarship of Teaching and Learning Annual International Conference (Haigh, 2010). Absent from most lists of conferences, however, is the annual Stellenbosch University Conference on the Scholarship of Teaching and Learning (six times) in South Africa. Hutchings et al. (2011) identify Australia, Canada, Hong Kong, Ireland, New Zealand, and the United Kingdom as countries outside the USA where there are SoTL practitioners, advocates, supporters, and organizations "especially, though not exclusively" (p. 18).

A variety of voices are now entering the SoTL "commons" requesting a larger view of context, one that includes the "political, cultural, [and] institutional, that shape what happens in the 'classroom"' (Looker, 2011, p.29). In the same issue of the International Commons containing Reynolds' report, Liddell (2008) ponders how the representation of people of colour in SoTL can be increased. What she found missing at the 2008 ISSOTL Conference was "a body of faculty representing institutions with primarily students of color" (2008, p. 8). She attributes this "invisibility" to a widespread lack of resources in these institutions. Lack of resources, power relations, and rich-poor divide also affect higher education in Sub-Saharan Africa (Scott, 2009). Transforming higher education (and participation) in Sub-Saharan Africa (with contributions from SoTL) requires that "assumptions must differ significantly from those of the developed Western world" if we are to analyse and address African contexts, where "only a thin layer of the population have access to good educational opportunities" (Scott, 2009, p. 2). Kwo (2007)asks how "poverty affect[s] the way we see "learners' and SoTL" (p. 3), subtly reminding us that SoTL is currently centred in wealthy liberal democracies.

Joëlle Fanghanel (2010) identifies fifteen questions relevant to "expanding the notion of SoTL beyond the confines of the classroom." The following four are relevant to this discussion:

- Are SoTL methodologies theoretically informed and how?

- Is theory a meaningful area of concern for SoTL?

- Is disciplinarity a stumbling block for SoTL?

- Can SoTL travel beyond English-speaking countries and how? 
The first three of these represent familiar SoTL territory, but the last is an emerging issue. In Revisiting the Chinese Learner: Changing Contexts, Changing Education, Chan and Rao (2009) suggest that "pedagogy and learning are influenced by the sociocultural context, and in particular the value and belief systems in the societies in which they are embedded" (p.18). Li (2009) contrasts radically different beliefs (held both historically and in the present) about learning in Western culture and Chinese culture, the first holding to concepts of "mind, reasoning, inquiry, and objective knowledge"; the other to "personal effort, endurance of hardship, perseverance, concentration and humility"(p.37). $\mathrm{Li}$ concludes that Western assumptions about learning are not easily applied to learners in non-western cultures: "The reason is quite simple: these concepts and theories were developed by Western researchers to study Western people based on Western cultural norms and values" (Li, 2009, p. 43).

The solution is to study learners themselves, in their own cultural contexts. Looker (2011) and $\mathrm{Li}$ (2009) suggest that we cannot think of learning as ever taking place in a context free of cultural influences. The titles of two well-known books from the USAHow People Learn: Brain, Mind, Experience, and School (Bransford, 2000) and How Learning Works: 7 Research-Based Principles for Smart Teaching (Ambrose, 2010) -imply, however, that approaches to learning operate in a culturally neutral context. $\mathrm{Li}$ (2009) suggests that "mind" is a particularly Western concern, so the first title might be contextualised as How People Learn in Western Culture. On the other hand, another book, Revisiting the Chinese Learner immediately declares its context.

As this brief literature review shows, there are gaps in the SoTL literature that result from exclusion of specific voices, and assumptions made in SoTL practice that do not apply easily to non-Western/non-English speaking learners. These gaps need to be plugged, and the assumptions need to be made more explicit, questioned, and justified if SoTL is to reach out to a much wider, more heterogeneous international community than it has done so far.

A question we would ask here is whether the gaps and assumptions are, in the terms of Scollon et al. (2012), created by a discourse system-SoTL — that is engaged "more or less unconsciously" as a particular discourse system and therefore looks to those who participate in it as more general, and even "natural," than it is. From our position, we might ask why we would care about this. In the section below, we explain how addressing these gaps could benefit SoTL by enlarging the cultural field within which teaching and learning might be understood and why we should care to contribute to SoTL.

\section{UNEXPLORED AUDIENCES, ASIAN PERSPECTIVES}

In outlining our personal trajectories above, our position is a simple but troubled one. We have experienced various dimensions of exclusion from an important conversation in teaching and learning, in part because of our own somewhat late entry into the field, ${ }^{5}$ and also because of the following factors:

1. our physical location in Asia poses a geographical-cultural disconnect from the SoTL centres, which amplifies the psychological distancing that Asian scholars often experience in many fields ${ }^{6}$;

2. a methodological solipsism within SoTL scholarship that originated from a predefined context-based point of departure, which has shaped the community's un- 
derstanding of what constitutes "relevant" or "important" SoTL questions. These in turn have determined the direction in the search for the "right" answers, the "right" data, strategies, and methods for conducting scholarly investigations into teaching and learning practices.

3. an ideological exclusion that arose because of a pre-established realm of dominance, and that dominance exerted by the particular culture/community has replicated itself and amplified the isolation experienced by distantly located minority voices.

This section explicates these three dimensions of isolation and explores the notion of "unexplored audiences" introduced by Nancy Chick and Gary Poole in their call for contributions to this journal, which we readily took up because it resonated with us here in a Southeast corner of Asia, Singapore. We might however change "unexplored audiences" to "unexplored participants."

\section{Geographical isolation}

Asia (and to a large extent, Africa and South America) is often the 'forgotten' continent. In spite of internationalization and globalization, and in spite of by-now routine discourses about a borderless world, Asia only occurs to many scholars in the English-speaking world as a kind of afterthought. Much knowledge still flows from West to East, unilaterally, and many networks and compositions of specific networks have retained a 'Western' flavour. ${ }^{7}$ This is the case with the SoTL world as evidenced by the history of ISSOTL.

On the ISSOTL home page, one reads that the International Society for the Scholarship of Teaching and Learning was founded eight years ago in 2004, when it was constituted by "a committee of 67 scholars from several countries"-namely, USA (about 27 institutions listed), UK (10 institutions), Australia (two institutions), Canada (two institutions), New Zealand (one institution), and South Africa (one institution). In addition, as noted earlier, eight conferences have been hosted since 2004, mostly all in English-dominant countries-Bloomington, Indiana (2004), Vancouver, Canada (2005), Washington, DC (2006), Sydney, Australia (2007), Edmonton, Canada (2008), Bloomington, Indiana (2009), Liverpool, UK (2010) ${ }^{8}$, Milwaukee, Wisconsin (2011), and Hamilton, Canada (2012). Furthermore, the home page also listed 6 scholars who have been recipients of the "ISSOTL Leadership Awards"-four from American and two from Australian institutions. As can be discerned from scrutinizing the home page, the founders, the (conference) sites, and leadership are all based in the West, with the exception of two countries in the Asia-Pacific rim. It was in the third conference in Washington, DC that some Asian and African delegates from China, Gambia, Hong Kong, Nigeria, Philippines, and Taiwan first participated in the SoTL Annual Conference series. Though we do not have information about what percentage this Asian/African participation commanded in the "[j] ust under 800 scholars" that attended the DC conference, we do not expect them collectively to exert a dominant presence there. The minority status of Asia/Africa is evident in ISSOTL's eight-year history.

The less-than-visible presence of a large part of Asia on the SoTL map-i.e., the physical absence - translates into a psychological absence as well. The oft-heard saying 'out of sight, out of mind' is a painful experience for many of us located in Asia/Africa, because physical isolation brought on by geographical distance, over time, easily develops into a network's failure to recognize the necessity for a perspective that lies outside the 
realm of the Western hemisphere. While space and physical distance can be overcome, it is harder to break pre-set psychological, ideological barriers. This psychological isolation (i.e. of being systematically forgotten) is a form of symbolic violence in that voices that were once not heard (due purely to the lack of physical connections to the centre(s) of activity) will and have insidiously evolved into an un-investigated silence as a routine, systemic acceptance settles in. The absence of those voices is then somehow not missed or no longer missed because they have not been found to be necessary or to figure centrally in the discourse in the first place. Pat Hutchings' (2000) "taxonomy of questions" for example included "what works" and "what it looks like," but starkly missed out on "works where." Location, even if unintentionally, seems to have been theorized into the dominant discourse where the Western location is unconsciously amalgamated with the universal and treated as default 'common sense' and other locations are theorized out of the picture totally. We argue here that ' what works where' is a critical question to ask and has unfortunately not been asked, for as Looker (2011) has argued, discussions about teaching and learning are not and cannot be free from the specifics of particular cultural contexts. Students outside the realm of the well-investigated West are in this sense the un- or under-investigated, and the scholars in Asia (and Africa) the untapped researchers. With both of these groups, a battery of unasked questions, approaches, perspectives, and classroom contexts (and answers) remain buried and silenced. ${ }^{9}$ In this context of physical and psychological exclusion, the invitation extended to one of the authors of this paper to be part of the Editorial Board of ISSOTL's new journal, Teaching \& Learning Inquiry, and the subsequent invitation to contribute an article on the Asian perspective on SoTL issues were both deeply welcomed, and immediately embraced as valuable opportunities for us to share our perspectives.

The exclusion we talk about, however, does not occur in a single direction. While it is important to think about why Asia is left out in the SoTL conversation, it is also critical to think about the nature of the discourse system of SoTL, and why it has not attracted Asian participation (or the participation of other parts of the world)? The lack of resonance both in methods and ideology for Asian participants is keenly felt, and it is to these other exclusions that we will now turn our attention.

\section{Methodological solipsism}

An underlying assumption in the scholarship of teaching and learning is that "teaching and learning must be viewed in the context of the specific class being taught" (Bernstein, 2011 , p. 1). And while context matters, the point is to be able to go beyond the specific context in order to inform others. Not to be capable of generalization is to risk assigning SoTL work to (disciplinary) silos (Healey, 2008.) Recognizing this problem of generalizability, Schroeder (2007) asks how "classroom-based questions and findings" can be formulated and investigated so as to have an impact on a whole institution. One of her answers is that SoTL should operate within a research framework that is both credible and evidence-based in order to be persuasive to colleagues outside the specific context of investigation. Investigations made in a specific context must be made both internally meaningful and coherent and externally meaningful and comprehensible. Arguments about the role of theory (and its explanatory power) insert themselves here, as well.

This does not, however, address the dimensions or orders of magnitude of the context itself (although theory may have the ability to make contexts and fault lines more 
visible). If we are to understand why the scholarship of teaching and learning has bypassed Asia and other parts of the world, we need to ask what the significant layers of context are that influence what happens in that local classroom. We also need to ask whether certain methodological approaches are themselves culturally determined. Reading various contributions by reviewers of SoTL articles concerning what they look for in a SoTL article (IJ-SOTL, Vol.5) provides some insight into this question by the conspicuous absence of certain criteria, such as evidence of international citations in all articles, attempts at crosscultural collaborations (a form of comparative SoTL), or an acknowledgment by authors that they work within a particular cultural context-being explicit, in other words, about one's own accent. As we shall suggest, these criteria might become part of a new protocol for the scholarship of teaching and learning as a means of extending its reach into Asia and other parts of the world, and as a way of being genuinely international.

Education operates within a socio-economic context (Davis \& Chandler, 2008; Boshier \& Huang, 2008) and a broader cultural and historical context (DeHaan, 2008; Nisbett \& Miyomoto, 2005; Li, 2009). Also, the way education is valued in different cultures makes a difference to what happens in the classroom, and how students and teachers respond to one another (Li \& Chang, 2001). There are real differences in beliefs about how learning occurs across cultures, some of which may reach back to the way language is learned. Nisbett (2003) and DeHaan (2008), for example, both point to how East Asian languages emphasise verbs (and relationships) in children's language acquisition, whereas European languages emphasise learning nouns (and the isolation of objects). This influences perception and of course formal learning. Such cross-cultural differences ought therefore to be taken into consideration in SoTL work.

It is possible to argue, as $\mathrm{Li}$ (2009) does, that much research into teaching and learning is based on a Western model of decontextualised individual psychology that excludes cultural contexts. In so doing, this kind of research lends itself to universalising. A book title like How People Learn is a case in point. What it signifies is an assumption of universality. It may be that the problem for SoTL in reaching a wider readership, or applicability, is that although it is localised in a particular kind of (physical and occasionally virtual) classroom that is not sufficiently contextualised, it suffers from a Western tendency to isolate objects of investigation. If we enlarge the context and take account of greater contextual complexity, or even think of teaching and learning as essentially situated, we may find a different approach to the scholarship of teaching and learning that is (paradoxically) more inclusive.

Bloch-Schulman (2012) provides a very useful term "transfer unfriendly"(p. 18) to describe this lack of context. He argues that in some writing about the pedagogy of philosophy, good practice is often equated (in a teacher-centric way) to providing clear and precise arguments to the reader that can in turn be passed on to students. What this pedagogical writing lacks is a discussion of the "concrete circumstances and contexts in which the authors work [in the classroom]" and there are serious uninspected assumptions about the transferability of their work to other contexts. Transferability relies on the disclosure of context and, we would argue, difference.

\section{Ideological exclusion}

Ideological exclusion is a double-edged process: it restricts one set of thinking by putting limits on its own scope while at the same time keeping another set of ideas out. 
While it can be a risky business to overgeneralise about cultural differences and characteristics, it is culturally biased to pretend they do not exist. To do so is necessarily to assume that one's own cultural values apply elsewhere. Nisbett (2003) begins his study The Geography of Thought: How Asians and Westerners Think Differently...and Why by explaining how a brilliant Chinese student challenged him to see his own cultural boundaries. He acknowledges that until then, he had been a "lifelong universalist concerning the nature of human thought" (p. xiii). This chimes with an observation made by Li (2009) about some research undertaken by Carol Dweck (2009) on children's intelligence. In relation to Dweck's work, Li suggests that educational research in the United States can make it appear "as if the United States were not a culture" (p. 40), the equivalent perhaps of not recognizing that like everyone else you have an accent. According to Nisbett, the tendency to universalise is itself firmly part of a Western tradition. In contrast, Asians, he says, pay more regard to context, and situational factors have more importance in Asian cultures than they do for Westerners, who frequently do not even perceive context. These may be reasons why the Scholarship of Teaching and Learning, which does not seem to interrogate its own cultural embeddedness, does not have greater cross-cultural reach.

The scholarship of teaching and learning is not neutral territory. As it has been formulated so far, it decontextualises teaching and learning from deeper cultural practices and particular socio-economic conditions. Fincher and Tenenberg (2011) hit on a similar point when they suggest that the scholarly forms of SoTL arise from a rhetoric that "scientises teaching." While they do not explain what they mean by "scientising," the tendency to isolate teaching and learning to a classroom without accounting for the larger socio-cultural and even political issues mimics Nisbett's claim that it is a deeply ingrained tendency of Western thinking to isolate objects of study from contexts in a way that East Asian thought does not. Through a series of investigations undertaken by him and many others, Nisbett demonstrates that Asian preferences for situational wholeness and complexity and for seeing identity in terms of relationship rather than individual self-containment have a profound effect on the "ways knowledge is organized more generally" (p. 135). Many of Nisbett's conclusions are echoed in Li's exploration of Chinese and American students' models of learning, where the most significant purpose of learning for the Chinese students is the need "to perfect oneself morally" (p. 49), whereas for American students it is about the development of mind and understanding.

Bringing the discussion back to our own Asian context, the complaint made by faculty in Singapore that SoTL studies conducted in America or the UK are not appropriate to the local context indicate their experience of a genuinely different context, which includes the traditions of learning students bring with them to university from school. To these faculty members, some SoTL coming from Western countries are transfer unfriendly. Dehaan (2008) notes that Asian students coming to university "have different levels [and styles] of preparation than Americans" (p. 5). And in an observation that may challenge comparability of teaching and learning practices within a particular disciplinary area, he notes that in secondary schools, science and math are integrated across disciplines in India and China, whereas in the US they are stratified. This has implications for the way students see the relationships among different subjects. The pervasive exam system in Asian countries (often seen as iniquitous in terms of current Western educational values) will persist, Li claims, because it is embedded in a system of belief about self-improvement through effort and equality, married to opportunity for a better life. 
This exam system, very different from the system of student assessment in say, Australia, cannot be understood unless the structure of belief in which it operates is understood. Such issues cannot be investigated in isolation from a larger context. The ideologies driving them are different, and the outcomes they may yield are expected to be different.

How does this affect the Scholarship of Teaching and Learning, especially if it is to be regarded as an international field of scholarship rather than a Western field of scholarship? How can Asia (and by extension African countries, South American countries, the Middle East, and so on) play an equal role? It is our belief that this is not a question of extending the boundaries through a process of assimilation, by focusing our attention on (say) Asian classrooms as well as those in Western countries. Importantly, this has got to be a process where different assumptions and practices are legitimized as worthy of investigation and as having significant perspectives to enlighten the scholarship, just as all of us by now are aware of the need to respect differences in accents.

\section{CONCLUDING REMARKS}

We began this paper by relating our personal journeys through the teaching and learning world, a journey that was marked by a peripheral location, at a distance from the centre of SoTL activities. The isolation we have felt with respect to SoTL activity in particular and the SoTL network in general has resulted in a disconnect in the way we have thought about SoTL discourse and debates; much of it seemed alien to us, and the debates seem difficult to relate to.

Our Asian context means that we deal with a student and teacher context that is complex in many ways, in the assumptions they hold about student-teacher dynamics, the purpose of education, the preferred style of classroom practice, the challenges they face, the larger economy (social, cultural, and political) in which they are located, and so forth. All of these differences in details of everyday living in our world and the disjuncts experienced on the teaching/learning front are the consequence of geography (our embeddedness in a particular kind of economy, our distance from the established or dominant centres of discourse), which influences our methods and the questions we need to ask. These in turn shape our ideology and define the gaps between dominant SoTL ideology and ours.

In raising these issues of difference and in calling for more awareness of such differences - that voices from the margins can usefully contribute to the exciting conversations that radiate from the centre of discourse-what we hope to have done is a form of consciousness raising, such that questions of what works where, how, and why will be embraced as essential to the scholarship as defined by practitioners located at the centre of SoTL discourse. We therefore hope to work towards a time when differences in accents are valued precisely because they are different, and not merely tolerated, or worse assimilated and homogenized into some standard rhetoric.

Negotiating a space somewhere between liberal individualist and communitarian claims in terms of the politics of difference, Young (1990) suggests we consider a model of social differentiation without exclusion, "a being together of strangers in openness to group difference" (p. 256). This might be a useful metaphor for the expansion of SoTL into different parts of the world. Importantly, Young suggests that it is through the assertion of both the "value and specificity" of the culture of marginalised groups the dominant culture becomes relativized. 
What we are suggesting here is not just an expansion of the centre, but a form of de-centering or relativizing, such that in future, all those who approach SoTL will be reflectively and reflexively aware of their own accents in the way they investigate their local context of teaching and learning.

\section{EPILOGUE}

Having journeyed across continental distances from around the ideological edges of discourse and finally to arrive at this point where we attempt to open a conversation on the platform of a SoTL journal, we hope that our account of the gaps in SoTL practices will be actively addressed in the near future. If indeed we all agree that alternative viewpoints, as we (and Lisa Delpit) have argued, can invaluably enrich SoTL development, then accented voices like ours ought to be embraced with their cultural nuances and differences intact, and not just homogenized and absorbed into the mainstream rhetoric. Our hope then is simple: that SoTL will no longer prove to be such "an alien territory" for those of us located outside the West and for those uninitiated in SoTL-speak, and that "[our] funny accent [s]" will one day be part of the fabric that an international SoTL community should aspire to become.

Chng Huang Hoon is an Associate Professor in the Department of English Language and Literature, and an Associate Provost (Undergraduate Education) at the National University of Singapore.

Peter Looker is the Associate Director for the Centre for Excellence in Teaching and Learning at Nanyang Technological University, Singapore.

\section{NOTES}

1. By 'Asian,' we refer to more than just our location outside the Western world. More importantly, 'Asian' indexes, as the paper argues, an ideologically excluded audience, an exclusion borne both out of our physical and pyschological location outside the centre of discourse.

2. Nancy Chick made the point to us, quite rightly, "what does it mean to be a SoTL expert? Most, if not all, of us come to SoTL after we've become experts in our disciplines, holding our highest degrees within the disciplines, not within SoTL." This is true, but the fact is, over the past decade, there are some names that are fully recognized in the field, and there is a discourse that emanates from a network of individuals that others situated at the margins have not found easy to access or understand.

3. Thanks to Gary Poole for permission to lift this quote from his email exchange on the subject.

4. These are perhaps not his precise words, but they are close.

5. Though it is true that many of us currently involved in teaching and learning entered the field late, having spent a greater part of our earlier career in a disciplinary domain before moving into explorations in the education realm, it is nevertheless important to remember that some of us occupy the more privileged positions of getting in earlier than others, and subsequently were able to define the field of investigation, due sometimes to location, to a network of relevant contacts, and to a shared sphere of ideological inclinations.

6. Australia and New Zealand also experience geographical distance from the North AmericaEurope axis, but they obtain a degree of cultural, or discourse system, inclusion. 
7. We understand that it is often risky and reductionist to talk in these binary 'West,' East,' 'Western' terms, but in a segment about geographical location, it is difficult to avoid such labels. But we understand that these are convenient handles and may not necessarily do justice to all regions falling within these broad terms.

8. Keith Trigwell approached Singapore about the possibility of collaborating in the 2010 conference, but due to its own prior commitments to other conferences, Singapore felt unable to take this up during that period.

9. Our point about 'unexplored participants' in the Asian world should include the many students of non-Western origins who are currently being educated from within a classroom, physical or virtual, in the Western hemisphere. As noted earlier in the paper, today's classrooms all over the world are increasingly heterogeneous as students move across borders to access education in an institution of their choice. For mainstream SoTL discourse to speak from a default, English-speaking, Western-centric perspective not only excludes audiences outside the West, but in fact also neglects the thousands of non-Western students who are already sitting in classrooms in the West. See, for instance, Lisa Delpit's important point about the exclusion of low-income children and children of colour in mainstream interactions through, among other factors, the assumptions we make (i.e. the "unexamined backdrop" of our own practices) and the imposition of 'Standard'English. Her call for the recognition of alternative worldviews is detailed in Other People's Children: Cultural Conflicts in the Classroom (2006). We thank our anonymous reviewer for sharing this very important observation with us.

\section{REFERENCES}

Ambrose, S. A. (2010). How learning works: Seven research-based principles for smart teaching. San Francisco, CA: Jossey-Bass.

Bernstein, J. L. (2011). Identifying High Quality SoTL Research: A Perspective from a Reviewer. International Journal for the Scholarship of Teaching and Learning, 5(1), 1-2. Retrieved from http://academics.georgiasouthern.edu/ijsotl/v5n1/ReviewersEssays/Bernstein/index.html

Bloch-Schulman, Stephen. (2012). "The Socratic Method: Teaching and Writing about Philosophy's Signature Pedagogy." In N.L. Chick, A. Haynie, \& R.A.R. Gurung (Eds.), Exploring More Signature Pedagogies: Approaches to Teaching Disciplinary Habits of Mind (pp. 15-26).

Boshier, R., \& Huang, Y. (2008). In the House of Scholarship of Teaching and Learning (SoTL), teaching lives upstairs and learning in the basement. Teaching in Higher Education, 13(6), 645-656.

Boshier, R. (2009). Why is the Scholarship of Teaching and Learning such a hard sell? Higher Education Research \& Development, 28(1), 1-15.

Bransford, J. (2000). How people learn: Brain, mind, experience, and school. Washington, D.C.: National Academy Press.

Brawley, S., Kelly, T. M., \& Timmins, G. (2009). SoTL and national difference: Musings from three historians from three countries. Arts and Humanities in Higher Education, 8(1), 8-25.

Brew, A. (2011). Higher education research and the Scholarship of Teaching and Learning: The pursuit of excellence. International Journal for the Scholarship of Teaching and Learning, 5(2), 1-4. 
Chan, C. K., \& Rao, N. (2009). Moving Beyond Paradoxes: Understanding Chinese Learners and Their Teachers. In C. K. Chan \& N. Rao (Eds.), Revisiting the Chinese learner: Changing contexts, changing education (pp. 3-32). Hong Kong: Springer.

Clegg, S. (2008, October 31). The Struggle for Connections. ISSOTL: Conferences. Retrieved August 28, 2012, from http://www.ISSOTL.org/past_ISSOTL/2008proceedings.html

Davis, W. E., \& Chandler, T. J. (1998). Beyond Boyer's scholarship reconsidered: Fundamental change in the university and the socioeconomic systems. The Journal of Higher Education, 61(1), 23-64.

DeHaan, R. L. (2008). National cultural influences on higher education. In R. L. DeHaan \& K. M. Narayan (Eds.), Education for innovation: Implications for India, China and America. Rotterdam: Sense Pub.

Delpit, Lisa D. (2006). Other People's Children: Cultural Conflicts in the Classroom. 2nd ed. New York: New Press. Print.

Dewar, J. M. (2008). An apology for the scholarship of teaching and learning. Insight: A Journal of Scholarly Teaching, 3, 17-22.

Draeger, J., \& Price, L. (2011). Which way to SoTL utopia? International Journal for the Scholarship of Teaching and Learning, 5(1), 1-13.

Fanghanel, J. (2010). Foreword (J. Fanghanel, D. Bernstein, M. Huber, D. Berthiaume, D. Warren, T. Roya, et al., Eds.). In Disciplines, Pedagogies and Cultures for SoTL. Retrieved August 29, 2012, from http://www.heacademy.ac.uk/assets/EvidenceNet/sotl_proceedings/Proceedings _LondonSoTL_2010.pdf

Fincher, S., \& Tenenberg, J. (2011, April 13). The scholarship of cockfighting. The London Scholarship of Teaching and Learning 8th International Conference Proceedings 2010. Retrieved July 30, 2012, from http://faculty.washington.edu/jtenenbg/publications.html

Gossman, P., Haigh, N., \& Xiaomin, J. (2009). The Status of the Scholarship of Teaching and Learning (SoTL) in New Zealand Universities: Three Case Studies (Rep.). AKO AOTEAROA National Centre fo Tertiary Teaching Excellence.

Gurm, B. K. (2009). Is all scholarship equally valued? Fusion and horizons on the definition and status of scholarship. International Journal for the Scholarship of Teaching and Learning, 3(2), 1-10.

Haigh, N. (2010, August). The Scholarship of Teaching \& Learning-a practical introduction and critique.-Ako Aotearoa. Retrieved August 28, 2012, from http://akoaotearoa.ac.nz/sotl

Healey, M. (2000). Developing the scholarship of teaching in higher education: A disciplinarybased approach. Higher Education Research and Development, 19(2), 169-189.

Healey, M. (2008, January). "On discipline-based approaches to SoTL” ISSOTL: Newsletter. ISSOTL: Newsletter. Retrieved August 28, 2012, from http://www.ISSOTL.org/newsletter.html

Hutchings, P., \& Shulman, L. (1999). The Scholarship of Teaching and Learning: New elaborations, new developments. Change, 31(5), 10-15.

Hutchings, P. (2000). Opening lines: Approaches to the scholarship of teaching and learning. Menlo Park, CA: Carnegie Foundation for the Advancement of Teaching. 
Hutchings, P., Huber, M. T., \& Ciccone, A. (2011). The scholarship of teaching and learning reconsidered: Institutional integration and impact. San Francisco, CA: Jossey-Bass.

Kreber, C. (2007). What's it really all about? The Scholarship of Teaching and Learning as an authentic practice. International Journal for the Scholarship of Teaching and Learning, 1(1), 1-4.

Kwo, O. (2007). SoTL in the commons: Elephant, authenticity and journey. International Journal for the Scholarship of Teaching and Learning, 1(2), 1-4.

Li, J. (2009). Learning to self-Perfect: Chinese beliefs about learning. In C. K. Chan \& N. Rao (Eds.), Revisiting the Chinese learner: Changing contexts, changing education (pp. 35-70). Hong Kong: Springer.

Li, X., \& Chang, S. (2001). A Positive Cultural Perspective on Rote Learning in China: An analysis of views from 100 Chinese learners in English. BALEAP. Retrieved August 28, 2012, from http://www.baleap.org.uk/home

Liddell, J. (2008, January). "On increasing representation of people of color in SoTL" ISSOTL: Newsletter. ISSOTL Commons: Newsletter. Retrieved August 28, 2012, from http://www .ISSOTL.org/newsletter.html

Looker, P. (2011). Globalising the local: The scholarship of teaching and learning in a larger context. Journal of the NUS Teaching Academy, 1(1), 21-31.

McKinney, K. (2007). Enhancing learning through the scholarship of teaching and learning: The challenges and joys of juggling. Bolton, MA: Anker Pub.

Nisbett, R., \& Miyamoto, Y. (2005). The influence of culture: Holistic versus analytic perception. Trends in Cognitive Sciences, 9(10), 467-473.

Nisbett, R. E. (2003). The geography of thought: How Asians and Westerners think differentlyand why. New York: Free Press.

Prosser, M. (2008). The Scholarship of Teaching and Learning: What is it? A personal view. International Journal for the Scholarship of Teaching and Learning, 2(2), (1-4).

Reynolds, L. (2008, January). "Multinational Conversation about Roles of SOTL Scholars" ISSOTL: Newsletter. ISSOTL: Newsletter. Retrieved August 28, 2012, from http://www.ISSOTL .org/newsletter.html

Schroeder, C. M. (2007). Countering SoTL marginalization: A model for integrating SoTL with institutional initiatives. International Journal for the Scholarship of Teaching and Learning, $1(1), 1-9$.

Scollon, R., Jones, R. H., \& Scollon, S. B. (2012). Intercultural communication: A discourse approach. Malden, MA: Wiley-Blackwell.

Scott, I. (2009). Towards an Agenda for SoTL in Africa? International Journal for the Scholarship of Teaching and Learning, 3(1), 1-8.

Stefani, L. (2011). Current perspectives on SoTL. International Journal for the Scholarship of Teaching and Learning, 5(1), 2-5.

Trigwell, K., Martin, E., Benjamin, J., \& Prosser, M. (2000). Scholarship of teaching: A model. Higher Education Research and Development, 19(2), 155-168.

Young, I. M.. (1990). Justice and the Politics of Difference. Princeton, NJ: Princeton UP, 1990. Print. 